\title{
Identification of Armillaria nabsnona in Gastrodia Tubers
}

\author{
Haruo Sekizaki, ${ }^{* a}$ Shiro Kuninaga, ${ }^{*, b}$ Mizuho Yamamoto, ${ }^{a}$ Sandra Naomi Asazu, ${ }^{a}$ Satoko Sawa, ${ }^{a}$ \\ Mareshige Kojoma, ${ }^{a}$ Ryozo Yokosawa, ${ }^{a}$ and Naotoshi Yoshida ${ }^{a}$ \\ ${ }^{a}$ Faculty of Pharmaceutical Sciences, Health Sciences University of Hokkaido; and ${ }^{b}$ School of Dentistry, Health Sciences \\ University of Hokkaido; Ishikari-Tobetsu, Hokkaido 061-0293, Japan. \\ Received December 26, 2007; accepted March 20, 2008; published online April 22, 2008
}

\begin{abstract}
The symbiosis between Armillaria species and an achlorophylous orchid Gastrodia elata BLume has been reported. The main species described as a symbiont is Armillaria mellea (VAHL: Fr.) Kummer, known widely as a primary root rot pathogen. Samples collected from the rhizomorphs attached to the tuber of $G$. elata were separated and analyzed. Molecular analysis based on sequencing of the intergenic spacer 1 (IGS-1) and internal transcribed spacer (ITS) regions of the ribosomal DNA (rDNA) was performed, coupled with restriction fragment length polymorphism (RFLP) of the IGS-1 region. Cultural morphology and features of basidiomata were also used to characterize the isolates. Phylogenetic analysis and morphological data strongly suggested that the fungus present in the tubers of $G$. elata is Armillaria nabsnona. This is the first report of occurrence of this Armillaria species in association with $G$. elata.
\end{abstract}

Key words Armillaria nabssnona; Gastrodia elata; symbiosis; molecular analysis; intergenic spacer one; internal transcribed spacer

Armillaria species (Basidiomycota, Agaricales, Tricholomataceae) are well known to be the cause of root rot and death to woody plants in boreal, temperate and tropical regions worldwide. ${ }^{1)}$ Generally this species has a broad variety of hosts, presenting pathogenic or symbiotic properties depending on the available substrate. ${ }^{1,2)}$

Armillaria has been identified as an associate in certain achlorophyllous taxa of Orchidaceae including Gastrodia elata BL. ${ }^{3,4)}$ and Galeola septentrionalis ReICHB. ${ }^{5)}$ Although many reports refer to Armillaria mellea as the main fungus symbiont of $G$. elata, ${ }^{3,6)}$ in recent years, other species of Armillaria have been found growing from mycorrhizal roots of this orchid. Five biological species, A. ostoyae (Romagnesi) Herink, A. gallica Marxmuller \& Romagnesi (as $A$. bulbosa (Barla) Kile \& Watling), A. jezoensis Cha \& Igarashi, $A$. sinapina Berube $\&$ Dessureault and $A$. singula Cha \& IgARASHI, associated with $G$. elata were reported in Japan. ${ }^{4)}$

In eastern traditional medicine, the tubers of this orchid have been used for the treatment of many kinds of diseases including headache, rheumatism, seizure, dizziness and circulation problems. ${ }^{7,8)}$ G. elata is considered as a difficult species to cultivate due to the need for different kinds of fungi colonization to achieve its full development. ${ }^{\text {) }}$ To increase the knowledge of the cultivation process and understand its relationship with the Armillaria, it is important to first identify which Armillaria species is involved in the association.

In past decades, the identification of Armillaria spp. was based on mating tests and morphological characteristics. ${ }^{2,9,10)}$ However, those methods are very limited due to the great number of biological species and similar morphological characteristics among them. ${ }^{11,12)}$ Furthermore, mating pairings require fresh haploid cultures that sometimes are not available and a long period is required to obtain results. ${ }^{13,14)}$

Methods based on molecular techniques are nowadays routinely used and provided a new perspective for phylogenetic and taxonomic studies. ${ }^{12,15-17)}$ PCR-RFLP analysis profiles of intergenic spacer 1 (IGS-1) have been successfully applied to the Armillaria species identification. ${ }^{12,13,18,19)}$

Sequencing of the internal transcribed spacer (ITS) and intergenic spacer 1 (IGS-1) regions ${ }^{14,20,21)}$ has also been used for identification. The ITS and IGS sequences available in the GenBank and the development of efficient software have provided a valuable tool for differentiation as well as for the detection of polymorphism and heterogeneity among species. The ITS and IGS-1 of the ribosomal DNA are known to be highly polymorphic enabling the accurate species differentiation of the Armillaria. ${ }^{11)}$ In some cases, however, ITS1 region sequences were proven to be nearly uniform among the Armillaria of northern hemisphere species. ${ }^{11)}$

The aim of this study was to apply molecular biological tools to identify which Armillaria species are involved in the association with $G$. elata. The ITS and IGS-1 regions of rDNA were amplified and sequenced for further comparison with other Armillaria species. PCR-RFLP of the IGS-1 region was performed with three different endonucleases. Morphological characteristics and compatibility tests were also used in the analysis.

\section{MATERIALS AND METHODS}

Fungal Isolation and Cultivation Fungal samples were harvested in July 2005, found in different root parts of $G$. elata, which grows naturally in the forest of the Health Sciences University of Hokkaido, in Japan. Several fungi were isolated from the rhizomorphs attached to the tuber surfaces (Fig. 1).

The samples were rinsed overnight with distilled water and sterilized with 5\% sodium hypochlorite solution for $60 \mathrm{~s}$. Samples from the fruit body, collected in September 2005, were cut to a size of approximately $5 \mathrm{~mm}$, rinsed with distilled water and sterilized with $70 \%$ ethanol. After sterilization, all the samples were carefully dried and plated onto malt extract agar medium (MEA) consisting of $2 \%$ glucose, $0.1 \%$ peptone, $2 \%$ malt dextrose, $2 \%$ agar, amended with $100 \mathrm{ppm}$ streptomycin to avoid bacteria proliferation. Fungal colonies grown after 4 weeks cultivation under $25^{\circ} \mathrm{C}$ temper- 
ature were transferred to new MEA media.

For single spore isolation, a $5 \mathrm{~mm}$ size fruit body was attached right side up to the cultivation petri dish lids using vaseline. Lids were placed onto the dish bottom, already filled with MEA media. The dish was incubated at room temperature for $60 \mathrm{~min}$ and gently rotated to scatter the spores in the culture media. The spores were grown in the same MEA and then transferred to fresh MEA, after substantial appearance of the colonies.

A total of 24 samples of the fungi were isolated from the rhizomorphs, the fruit body and sporefalls. Eight samples (Table 1) were chosen and subjected to DNA extractions according to slight differences in the culture characteristics. Tester strains of $A$. mellea purchased from NITE Biological Resource Center (Chiba, Japan) and A. nabsnona (Japanese tester strain 30987-3) kindly supplied by Dr. E. Nagasawa of the Tottori Mycological Institute (Tottori, Japan) were also cultivated and subjected to DNA extractions. Voucher specimens were preserved and stored.

DNA Extractions The fungal isolates were grown in $50 \mathrm{ml}$ malt extract broth, consisting of $2 \%$ malt extract, $2 \%$ glucose, $0.1 \%$ peptone, in complete dark at $25^{\circ} \mathrm{C}$. Tester strains were also obtained and also subjected to DNA extractions. After 4 weeks, mats of the mycelium were collected, rinsed with sterile distilled water, freeze dried at $-70^{\circ} \mathrm{C}$ for $24 \mathrm{~h}$ and lyophilized. The freeze-dried mycelium was ground into fine powder. Genomic DNA was extracted by mixing the pulverized mycelium with NTE buffer (100 mM NaCl, $30 \mathrm{~mm}$ Tris-HCl, 10 mм EDTA, 10 mм 2-mercaptoethanol) (pH 8.0) containing $0.5 \%(\mathrm{v} / \mathrm{v})$ Nonidet P-40 and centrifuged at

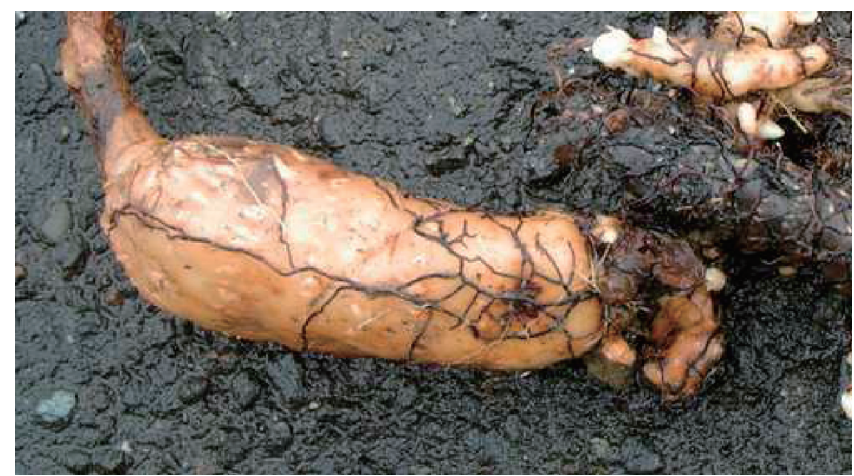

Fig. 1. Armillaria Rhizomorphs Attached to Gastrodia Tuber
$10000 \mathrm{rpm}$ for $1 \mathrm{~min}$. The pellet was resuspended in NSE buffer (100 mm NaCl, $200 \mathrm{~mm}$ sucrose, $10 \mathrm{~mm}$ EDTA) ( $\mathrm{pH}$ 4.0) before adding TES buffer $(10 \mathrm{~mm}$ Tris- $\mathrm{HCl}, 250 \mathrm{~mm}$ EDTA ( $\mathrm{pH}$ 9.2), 2.5\% SDS). The homogenate was incubated for $30 \mathrm{~min}$ at $55^{\circ} \mathrm{C}$. The solution was extracted with an equal volume of phenol:chloroform: isoamylalcohol $(50: 48: 2)$ and centrifuged at $10000 \mathrm{rpm}$ for $20 \mathrm{~min}$. The upper layer was mixed with 0.1 volume of $3 \mathrm{~m}$ sodium acetate, and then 0.54 volume of isopropanol. The DNA pellet was collected, rinsed with $70 \%$ ethanol and then dried under a vacuum.

PCR-RFLP of IGS Region The IGS- 1 region was amplified with primers LR12R (5' CTGAACGCCTCTAAGTCAGAA $\left.3^{\prime}\right)^{22}$ and O-1 (5' AGTCCTATGGCCGTGGAT $\left.3^{\prime}\right){ }^{23)}$ The PCR reactions were performed in a $50 \mu$ l mixture containing $50 \mathrm{~mm} \mathrm{KCl}, 20 \mathrm{~mm}$ Tris- $\mathrm{HCl}(\mathrm{pH} 8.4), 1.5 \mathrm{~mm}$ $\mathrm{MgCl}_{2}, 200 \mu \mathrm{M}$ of each of the four deoxynucleoside triphosphates, 5 pmol of each primer, $1.0 \mu \mathrm{l}$ of DNA template, and 2.5 units of Taq polymerase. Amplification was carried out with a Thermal Cycler MP (Takara, Ltd., Shiga, Japan.). Reaction parameters consisted of initial denaturing at $94^{\circ} \mathrm{C}$ for $2 \mathrm{~min}$, followed by 30 cycles of denaturation at $94^{\circ} \mathrm{C}$ for $40 \mathrm{~s}$, annealing at $50^{\circ} \mathrm{C}$ for $1 \mathrm{~min}$ and extension at $72^{\circ} \mathrm{C}$ for $1 \mathrm{~min}$, and final extension at $72^{\circ} \mathrm{C}$ for $10 \mathrm{~min}$. IGS-1 PCR products were then purified using QIAquick PCR Purification kit (Qiagen Inc., Valencia, CA, U.S.A.).

RFLP analysis of the IGS-1 PCR products was performed according to methods described by Fukuda and Ono. ${ }^{24)}$ PCR products were digested separately with three restriction endonucleases: Hinf I, Msp I and Hae III (Takara, Ltd., Shiga, Japan), following the supplier's instructions. Electrophoresis was carried out on 3.0\% Nusieve 3: 1 Agarose (Cambrex Bio Science Rockland, Inc., Rockland, ME, U.S.A.) and visualized with ethidium bromide, under UV light.

Sequencing of ITS and IGS Regions IGS-1 PCR products were submitted to a cloning method which was carried out using a Dyna Express TA PCR cloning kit (BioDynamics, Laboratory Inc., Tokyo, Japan). PCR cycle sequence reaction was performed using a Thermo Sequenase Primer Cycle Sequencing Kit (Amersham Biosciences, U.K. limited), according to the manufacture's instructions. Reaction was carried out with a thermal cycler MP (Takara, Ltd., Shiga, Japan) and consisted of 20 cycles of denaturation at $95^{\circ} \mathrm{C}$ for $30 \mathrm{~s}$, annealing at $55^{\circ} \mathrm{C}$ for $30 \mathrm{~s}$ and extension at $72{ }^{\circ} \mathrm{C}$ for $1 \mathrm{~min}$. After reaction, $6 \mu \mathrm{l}$ of formamide loading dye was added to each sample. Sequencing was performed

Table 1. Specimens of the Biological Species Submitted to DNA Extraction and Their Cultural Characteristics

\begin{tabular}{|c|c|c|c|c|}
\hline \multirow{2}{*}{ Isolates } & \multirow{2}{*}{ Origin } & \multirow{2}{*}{ Culture characteristics } & \multicolumn{2}{|c|}{ Accession number } \\
\hline & & & ITS & IGS \\
\hline C-3-3 & Rhizomorphs & Flat, crustose, dark brown & AB368926 & AB368921 \\
\hline C-4-3 & Rhizomorphs & Rhizomorphic & AB368927 & AB368922 \\
\hline C-7-3 & Rhizomorphs & Flat, crustose, dark brown & AB368928 & AB368923 \\
\hline S-40 & Spore & White and fluffy & & \\
\hline 78 & Fruit body & Rhizomorphic & AB368925 & AB368920 \\
\hline $\mathrm{F}-2$ & Fruit body & Flat, crustose, dark brown & & \\
\hline $\mathrm{F}-3$ & Fruit body & Rhizomorphic, dark brown & & \\
\hline F-4 & Fruit body & Flat, crustose, dark brown & & \\
\hline 31616 & Japanese Armillaria mellea tester strain (IF031616) & Rhizomorphic & & \\
\hline 31166 & Japanese Armillaria mellea tester strain (IF031166) & Rhizomorphic & & \\
\hline $30987-3$ & Japanese Armillaria nabsnona tester strain & White and fluffy & AB368929 & AB368924 \\
\hline
\end{tabular}


using a Hitachi SQ5500E Sequencer (Hitachi Co., Ltd., Tokyo).

The ITS regions (ITS-1, 5.8S and ITS-2) of the rRNA were amplified using primers ITS-5 (5' GGAAGTAAAAGTCGTAACAAGG 3') and ITS-4 (5' TCCTCCGCTTATTGATATGC $\left.3^{\prime}\right) .{ }^{25}$ ) PCR reaction was performed using the same conditions described for the IGS-1 region. PCR products were cloned and then sequenced equally as described previously.

DNA Sequences Similarity and Phylogenetic Analysis DNA similarity of the IGS-1 and ITS regions was performed using a DNASIS software package (HITACHI). Comparison of other Amillaria species was carried out using previously characterized sequence data from GenBank. Phylogenetic relationships among the four isolates and the other Armillaria strains were also determined by cladistic analyses of IGS-1 region. The sequences were aligned using the DNASIS software package. The alignment was manually edited in MacClade 4.0. ${ }^{26)}$ Regions of ambiguous alignment were excluded from further phylogenetic analysis. Other regions containing single-nucleotide insertion or deletion were included in the analysis, with gaps treated as missing data. Phylogenetic analysis was performed using the maximum parsimony criterion in PAUP* 4.0. ${ }^{27)}$ Branch support was assessed by bootstrap analysis based on 500 replicate heuristic searches using the option in PAUP*.

Mating Test The sporefalls were collected and plated onto MEA using the procedure described previously. For haploid-haploid pairings, the isolate S-40 which demonstrated a white and fluffy appearance, were paired with the haploid Japanese Armillaria nabsnona tester strain. Pairings were made by placing inocula $0.5 \mathrm{~mm}$ apart on a MEA culture media and incubated at $25^{\circ} \mathrm{C}$ for 3 weeks.

\section{RESULTS}

Basidiomata and Cultural Morphology Characteristics Basidiomata of this Armillaria species generally grows in mid September, when the temperature drops to approximately $15{ }^{\circ} \mathrm{C}$ at night. High humidity and adequate day temperature is also required. Basidiomata usually occurs in nature in clusters of 5 to 10 , fused at the attachment point in the base of a decaying tree root. The pileus varied from 4.5 $7 \mathrm{~cm}$ in diameter with a honey-brown color and appearing smooth and slimy on the surface, slightly concave at the disk center and slightly incurved in the margins. The stipe was creamy-white in color, measured $4.2-5.5 \mathrm{~cm}$ high and 2 $5 \mathrm{~mm}$ in diameter. The basidiospores measured $7-10 \mu \mathrm{m} \times$ $3-6 \mu \mathrm{m}$, smooth surface with an ovoid to sub-globose aspect.

Colonies that arose from basidiospores were characteristically white and fluffy with raised mycelium becoming dark brown, flat and crustose in appearance as they aged. In contrast, colonies resulting from the tissues of the fruit body and the rhizomorphs were consistently flat, crustose and sometimes rhizomorphic.

PCR-RFLP of IGS-1 The IGS-1 of the isolates was amplified by PCR and a single product was detected for all 8 isolates. The RFLP analysis performed using the three different restriction endonucleases resulted in the same restriction patterns among the 8 isolates. These restriction patterns demonstrated the same band patterns with $A$. nabsnona, clearly differing from those of $A$. mellea (Fig. 2).

ITS and IGS-1 Sequences and Phylogenetic Relationship ITS and IGS-1 sequence comparison between the isolated fungi with other Armillaria species deposited in the GenBank resulted in high homology with A. nabsnona (Table 2).

Four isolates (C-3-3, C-4-3, C-7-3, 78) and the Japanese $A$. nabsnona tester strain were submitted to sequencing. Similarity comparison of the ITS regions of C-4-3, C-7-3 and 78 demonstrated a 100\% match among them. The isolate C-3-3 had two mutation points and compared with the Japanese $A$. nabsnona tester strain, the similarity was $99.6 \%$. ITS comparison with other Armillaria deposited in the GenBank resulted in a high similarity with $A$. nabsnona, A. gallica, $A$. calvescens, A. cepistipes and A. sinapina (Table 2 ).

IGS-1 sequence comparison of the four isolates with the Japanese $A$. nabsnona tester strain resulted in a perfect similarity match. A deletion event consisted of $22 \mathrm{bp}$ from the 430th to the 451 st position counting from the $3^{\prime}$ end of LR12R primer was present in all isolates including the Japanese tester strain. Comparison of the IGS-1 region of the four isolates resulted in the highest similarity (94-95\%) with $A$. nabsnona deposited in the GenBank, while the four isolates shared a comparatively low value, ranging from 68 to 92\%, with the other Armillaria species (Table 2). In the parsimony tree (Fig. 3), the isolates associated with G. elata and the Japanese tester strain (30987-3) were grouped within the well-supported clade that corresponds to A nabsnona $(99 \%$ bootstrap support). Phylogenetic analysis of IGS-1 sequences

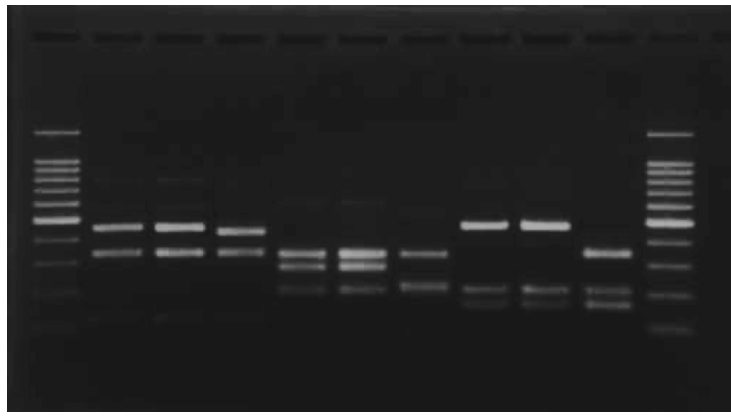

Fig. 2. Band Patterns of Msp I, Hae III, Hinf I Digestion Products of the IGS-1 Region of Our Isolate (1), A. nabsnona (2) and A. mellea (3)

Size markers (100 bp ladder) in both sides.

Table 2. Similarity Comparison of the ITS and IGS-1 Regions of Our Isolates with Other Armillaria Species Deposited in the GenBank

\begin{tabular}{|c|c|c|c|c|}
\hline \multirow{3}{*}{$\begin{array}{l}\text { Biological } \\
\text { species }\end{array}$} & \multicolumn{4}{|c|}{ Similarity comparison } \\
\hline & \multicolumn{2}{|c|}{ ITS-1, 5.8 S, ITS-2 } & \multicolumn{2}{|c|}{ IGS-1 } \\
\hline & $\mathrm{C}-3-3$ & 78 & $\mathrm{C}-3-3$ & 78 \\
\hline A. nabsnona & $98-99 \%$ & $99 \%$ & $94-95 \%$ & $94-95 \%$ \\
\hline A. gallica & $98 \%$ & $98-99 \%$ & $91 \%$ & $91-92 \%$ \\
\hline A. calvescens & $98 \%$ & $99 \%$ & $92 \%$ & $92 \%$ \\
\hline A. sinapina & $98 \%$ & $98 \%$ & $91-92 \%$ & $91-92 \%$ \\
\hline A. cepitispes & $98 \%$ & $98 \%$ & $90-91 \%$ & $90-92 \%$ \\
\hline A. tabescens & $90-91 \%$ & $91 \%$ & $91 \%$ & $91 \%$ \\
\hline A. mellea & $83-88 \%$ & $83-89 \%$ & $68-71 \%$ & $68-71 \%$ \\
\hline A. borealis & $97 \%$ & $97 \%$ & $90 \%$ & $91 \%$ \\
\hline A. ostoyae & $98 \%$ & $98 \%$ & $91 \%$ & $90-91 \%$ \\
\hline
\end{tabular}




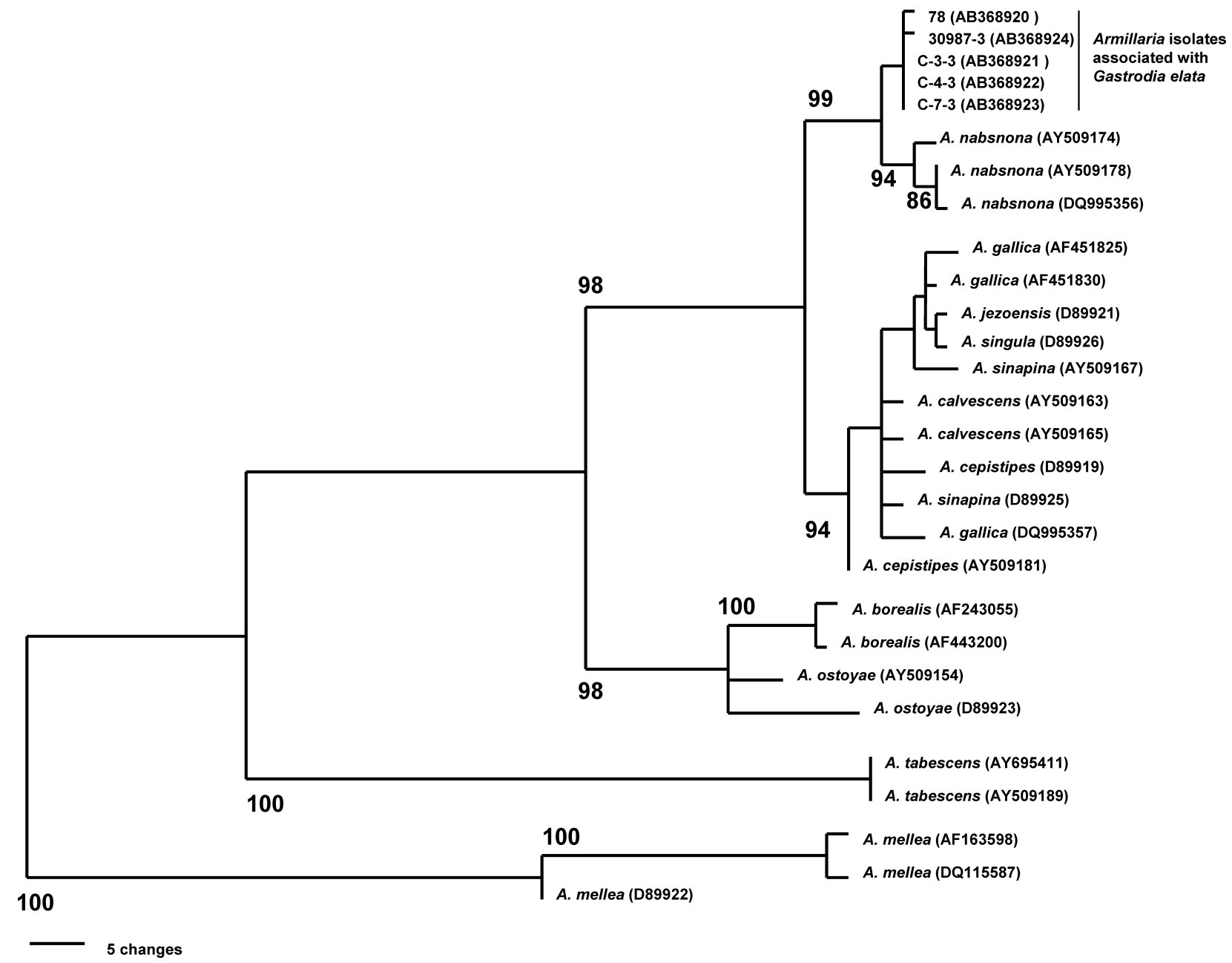

Fig. 3. One of the Most Parsimonious Trees Based on Heuristic Search Analysis of IGS-1 Sequences Showing the Placement of the Fungi Associated with Gastrodia elata among Different Species of Armillaria

Tree length is 317 steps with 245 phylogenetically informative characters. Consistency index $(\mathrm{CI})=0.820$, retention index $(\mathrm{RI})=0.895$, and rescaled consistency index $(\mathrm{RC})=0.734$. Percentage bootstrap support (500 replications) is shown above branches.

also indicated that the fungi isolated from $G$. elata in this study are apparently different from A. gallica, A. singular, $A$. sinapina, A. jezoensis and A. ostoyae previously isolated from mycorrhizal roots of this orchid.

Mating Test Pairing between haploid isolate and haploid Japanese $A$. nabsnona tester strain resulted in changes of morphology of haploid mycelia into the crustose type and stained the media dark brown. No black demarcation line was visible between the inocula.

\section{DISCUSSION}

Many studies refer to A. mellea as the main symbiotic species of $G$. elata. ${ }^{2,6,28)}$ However, recent studies have shown that other Armillaria spp. are involved. ${ }^{4}$ Our study, based on sequence similarity of the ITS and IGS-1 regions of the rDNA and PCR-RFLP and phylogenetic analysis of IGS-1 strongly suggested that the association of $G$. elata is with $A$. nabsnona.

Mating test was performed in order to analyze the compatibility of the isolates from the gastrodia tubers with the Japanese A. nabsnona tester strain. The tests resulted in a clearly compatible pairing of haploid isolates with this tester strain.

Analysis of the ITS region resulted in a perfect match within our isolates and the Japanese A. nabsnona tester strain. Sequences comparisons with other Armillaria deposited in the GenBank revealed significantly high similarity with $A$. nabsnona, A. gallica, A. calvescens, A. cepistipes and A. sinapina.

These results indicate that ITS sequences are highly conserved among these species. However, enough variability in the IGS-1 region was present enabling a clear distinction with these Armillaria species.

PCR-RFLP analysis of the IGS-1 region using $\operatorname{Hinf} \mathrm{I}$, Hae III and Msp I of our isolates produced restriction fragment patterns consistent with those found in A. nabsnona tester strain. Those results matched with those found by Fukuda et al. ${ }^{29)}$

The sequencing of the IGS-1 region demonstrated a perfect match between them and with the Japanese $A$. nabsnona tester strain. Comparison of our isolates with other $A$. nabsnona deposited in the GenBank indicated a deletion event consisted of $22 \mathrm{bp}$, between the 430th and $451 \mathrm{st}$ position from the $3^{\prime}$ end of the LR12R primer sequence. However, comparison of the IGS-1 region of our isolates with the data 
of other Armillaria species deposited in the GenBank resulted in the highest similarity with $A$. nabsnona, whether or not the deletion event was considered. Furthermore, phylogenetic analysis of the IGS-1 data also revealed a well supported group that corresponds with previously recognized $A$. nabsnona.

A. nabsnona is reported as a species distributed on the west coast of North America and its range was described primarily in hardwoods of riparian areas. ${ }^{30)}$ Ota et al. ${ }^{31)}$ have described the occurrence of $A$. nabsnona in the region of Honshu island, in central Japan. Based on mating tests, Mohammed et $a{ }^{32}{ }^{32}$ reported a compatible pairing of an isolate collected from Hokkaido Prefecture (Japan) with an Armillaria species described as NABS IX. Later, Volk et al. ${ }^{33)} \mathrm{de}-$ scribed NABS IX as A. nabsnona, a new species from western North America. The authors performed a compatibility test between NABS IX samples collected from North America and Japan, however, their result showed no compatible pairing between the Japanese and North America isolates. We believe that some peculiarities are present among the species that diverge from continents and in these cases mating tests might not be the best technique for the identification of Armillaria.

With respect to Armillaria species associated with $G$. elata, five biological species (A. ostoyae, A. gallica, A. jezoensis, $A$. sinapina, and $A$. singula) have been reported by Cha and Igarashi. ${ }^{4)}$ Furthermore, Mohammed et al. ${ }^{32)}$ reported a clearly compatible pairing of the isolates collected from $G$. elata with European and North American testers of A. gallica.

This is the first report concerning the association of $A$. nabsnona with $G$. elata based on a molecular level. However, it should be pointed out that as only a limited number of isolates were used in these studies more fungi sampling from the roots of $G$. elata, especially from different areas, would be necessary. Furthermore, the accurate identification of the fungi associated with $G$. elata might unveil its complex relationship and increase the knowledge of the cultivation process.

Acknowledgements We thank Dr. Eiji Nagasawa from Tottori Mycological Institute (Japan Kinoko Research Centre Foundation, Tottori, Japan) for kindly providing us the culture of $A$. nabsnona tester strain. This work was supported in part by a Grant-in-Aid for High Technology Research Programs from the Ministry of Education, Culture, Sports, Science and Technology of Japan.

\section{REFERENCES}

1) Hood I. A., Redfern B. D., Kile G. A., "USDA Agricultural Handbook
No. 691," USDA, Washington DC, 1991, pp. 122-149.

2) Anderson J. B., Korhonen K., Ullrich R. C., Mycologia, 71, 402-414 (1979).

3) Kusano S., J. Coll. Agric., 4, 1-65 (1911).

4) Cha J. Y., Igarashi T., Eur. J. For. Pathol., 25, 319-326 (1995).

5) Cha J. Y., Igarashi T., Mycoscience, 37, 21-24 (1996).

6) Xu J., Guo S., Chin. Med. J., 113, 686-692 (2000).

7) Lin J. H., Liu Y., Hau J. P., Wen K. C., Phytochemistry, 42, 549—551 (1996).

8) Zhao Y., Cao Q., Xiang Y., Hu Z., J. Chromatogr. A, 849, 277-283 (1999).

9) Korhonen K., Karstenia, 18, 31-42 (1978).

10) Anderson J. B., Korhonen K., Ullrich R. C., Exp. Mycol., 4, 87-95 (1980).

11) Chillali M., Idder-Ighili H., Guillaumin J. J., Mohammed C., Lung Escarmant B., Botton B., Mycol. Res., 102, 533-540 (1998).

12) Sierra A. P., Whitehead D. S., Whitehead M. P., Mycol. Res., 103, $1631-1636$ (1999).

13) Terashima K., Kawashima Y., Cha J. Y., Miura K., Mycoscience, 39 $179-183$ (1998).

14) Otieno W., Sierra A. P., Termorshuizen A., Mycologia, 95, 160-175 (2003).

15) Piercey-Normore M. D., Egger K. N., Bérubé J. A., Mol. Phylogenet. Evol., 10, 49-66 (1998).

16) Coetzee M. P. A., Wingfield B. D., Bloomer P., Wingfield M. J., Mycol. Res., 109, 1223-1234 (2005).

17) Kim M. S., Klopfenstein J., Hanna J. W., McDonald G. I., For. Pathol., 36, 145-164 (2006)

18) Harrington T. C., Wingfield B. D., Mycologia, 87, 280-288 (1995).

19) White E. E., Dubetz C. P., Cruickshank M. G., Morrison D. J., Mycologia, 90, 125-131 (2007).

20) Terashima K., Cha J. Y., Yajima T., Igarashi T., Miura K., Eur. J. For Pathol., 28, 11-19 (1998).

21) Coetzee M. P. A., Wingfield B. D., Kirisits T., Chhetri D. B., Bloomer P., Wingfield M. J., Plant Pathol., 54, 36-45 (2005).

22) Veldman G. M., Klootwijk J., DeRegt V. C. H. F., Rudi R. J., Nucleic Acids Res., 9, 6935-6952 (1981).

23) Duchesne L. C., Anderson J. B., Mycol. Res., 94, 266-269 (1990).

24) Fukuda M., Ono Y., Rep. Tottori Mycol. Inst., 37, 60-68 (1999).

25) White T. J., Bruns T., Lee S. W., Taylor G., "PCR Protocols: A Guide to Methods and Applications," ed. by White T. J., Innis M., Gelfand D. H., Sninsky J. J., Innis M. A., Academic Press, San Diego, 1990, pp. $315-324$.

26) Maddison D. R., Maddison W. P., "MacClade 4: Analysis of Phylogeny and Character Evolution. Version 4.05," Sinauer, Sunderland, 2002.

27) Swafford D. L., "PAUP*. Phylogenetic Analysis Using Parsimony (and other methods), Version 4," Massachusetts: Sinauer Associates, Sunderland, 2000

28) Wang H. X., Yang T., Zeng Y., Hu Z., Plant Cell Rep., 26, 253-259 (2007).

29) Fukuda M., Nakashima E., Hayashi K., Nagasawa E., Mycol. Res., 107, 1435-1441 (2003).

30) Banik M. T., Volk T. J., Burdsall H. H., Mycologia, 88, 492-496 (1996).

31) Ota Y., Matsushita N., Nagasawa E., Terashita T., Fukuda K., Suzuki K., Plant Dis., 82, 537-543 (1998).

32) Mohammed C., Guillaumin J. J., Berthelay S., Mycol. Res., 98, 607613 (1994).

33) Volk T. J., Burdsall H. H., Banik M. T., Mycologia, 88, 484-491 (1996). 